\title{
T-shaped engineers: getting ready for employability
}

\author{
Petra Kletzenbauer, Sonja Gögele
}

Department of Applied Computer Sciences, FH JOANNEUM, Austria.

\begin{abstract}
Even though knowledge transfer remains the starting point of any career, it is without a doubt that professional success goes beyond the acquisition of sound expert knowledge. In fact, the inevitable challenges of increasing flexibility on the labour market can only be mastered by embracing an interdisciplinary approach when educating future employees to meet the social and environmental standards and demands. In order to pursue a successful engineering career T-shaped engineers need to enter the labour market in order to pave the way to innovation. Based on an online survey among potential industry partners and a follow-up SWOT anaylsis at the faculty of Applied Computer Sciences, a training course was developed at the department of computing compromising communicative, social, entrepreneurial and innovational aspects - skills that usually go beyond the major classes of the curriculum. The research aims to show how a professionalization of students, being originally enrolled for a traditional computing degree programme, can make a difference in attaining a successful career and and thus further impact their overall future of employability.
\end{abstract}

Keywords: Employability; Key skills; T-shaped engineers. 


\section{Introduction}

Computing professionals are in demand worldwide. Apart from Austia, other European countries and even the US seek IT professionals since digitalization is the key player in almost every business. According to Bahler (2018) these professionals play "an increasingly popular and important role in the tech space" and thus IT graduates do have great opportunities landing well-paid and fulfilling jobs. Despite this quite promising outlook, a recently-conducted small-scale study at our deparment has shown a quite different picture. Although our IT gaduates do show an excellent adacemic profile, they often lack certain skills and competences which should help them to thrive in a globalized world.

These skills can be labelled as so called transversal skills as they usually unfold entrepreneurial skills, leadership qualities, problem-solving skills, an awareness for business ethics and (foreign) communication skills as well as critical thinking competences and interpersonal skills. Although the Bachelor curriculum at the IT department does have a quite comprehensive design - some courses do already cover these transversal skills - it seems that graduates miss to see what kind of additional qualifications they bring along to their job interviews and respectively later to their jobs. This notion has been further investigated in a recently conducted small-scale study among long-term industry partners and future employers. In form of five open-ended questions, we asked them to participate in a small survey to see if the investigation confirms our hypothesis of observing a lack of tranversal skills among our respective graduates.

Based on the results of the survey and a SWOT analysis at the faculty, an action plan was developed in order to increase the visibility of transversal skills. For this purpose a socalled training week, piloted during summer term 2018, was introduced which had the aim to prepare students better and more effiencitly for employability.

The paper at hand covers the main aspects of a T-shaped engineer before it briefly elaborates on the small-scale study conducted. In the final section, the professional training week is explained in detail. The paper finishes by discussing if such intiatives might be an appropriate way to raise awareness of students' potential outside their academic comfort zone.

\section{The T-shaped Engineer}

The concept of a T-shaped engineer, as shown in Figure 1, includes content expertise on the one hand and multi-disciplinary skills on the other hand. To visualize these abilities the "T" serves as a metaphor for describing the depth and breadth of a person's competences and skills. In doing so, the vertical leg on the $\mathrm{T}$ should reflect the depth of relevant skills and 
competencies in a single area whereas the horizontal one describes the ability to thinkoutside the box by acquiring and applying knowledge in fields of expertise other than one's own (see Tranquillo, 2017).

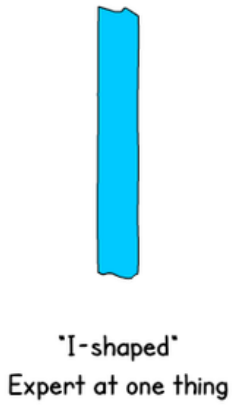

Expert at one thing

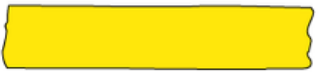

Generalist

Capable in a lot of things

but not expert in any

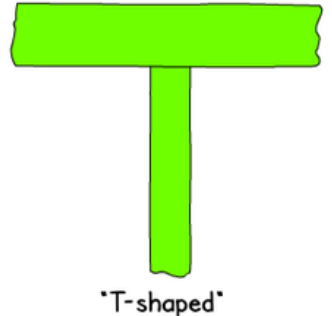

Capable in a lot of things

and expert in one of them

Figure 1. T-shaped Engineer Matrix (image by Jason Jip)

According to Grasso \& Brown Burkins (2010, p. 1) "the exciting future of engineering is beyond technological labels (e.g., mechanical engineer, electrical engineer, and chemical engineer), which represents for a "more cross-disciplinary, whole-systems approach to engineering that "emphasizes contextualized problem formulation, the ability to lead teamcentered projects, the skill to communicate across disciplines, and the desire for life-long learning of the engineering craft in a rapidly changing world. " In other words, tertiary education has to consider how "to cultivate professionals take on the most complex technological, social, environmental, and economic challenges facing today's societies" (ibid, p. 2).

\section{Methodology}

A mixed methods strategy was employed, in the form of an online survey and face-to-face discussions (SWOT analysis) within the faculty to better capture the complexity of the topic in question. For our online survey we designed five open-ended questions where we asked particiants to report on their point of view when it comes to describe the additional skills and competences of our IT graduates, what job-related issues have changed in recent years, which challenges future employees have to face and what suggestions they have to make students better prepared for the future. With this rather broad scope of questions industry partners had the chance to highlight all aspects of change that they associate with employability and transversal skills. The survey was distributed via surveymonkey and reached out to over 30 industry partners of which only 10 responded.

The survey was conducted in German and the following questions were outlined: 
1. In your opinion, how prepared are our students for employability in the $21 \mathrm{st}$ century? Apart from their expert knowledge, what kind of skills and competences are they already equipped with?

2. What has changed in terms of employability in recent years due to globalisation?

3. What kind of challenges in the world of work do future emyployees have to face?

4. When we speak of so-called transversal skills, what should these skills unfold?

5. What qualifications and training might be worth considering at tertiary level in order to increase the T-shaped mindset among our stundents?

The data from the survey were collected and a thematic analysis (see Braun and Clarke, 2006) was made based on the main principles of a T-shaped engineer. This form of analysis helped to shape the content of the survey in order to discuss the answers in more detail.

These results finaly led to a so-called SWOT analysis (see Gao and Peng, 2011). Gürel \& Tat (2017, p. 995) describe the SWOT Analysis as "a tool used for strategic planning and strategic management in organizations. It can be used effectively to build organizational strategy and competitive strategy. In accordance with the System Approach, organizations are wholes that are in interaction with their environments and consist of various subsystems. In this sense, an organization exists in two environments, one being in itself and the other being outside. It is a necessity to analyse these environments for strategic management practices. This process of examining the organization and its environment is termed SWOT Analysis". In other words, a SWOT anaylsis is an essential planning framework to evaluate not only an organization or a project but also other activities that might contribute to the success of a company. It helps managers to analyse a situation in depth. According to Gürel \& Tat (2017, p. 995) a "SWOT Analysis has two dimensions: internal dimension includes organizational factors, also strengths and weaknesses, external dimension includes environmental factors, also opportunities and threats".

Based on the SWOT analysis, an action plan for the faculty was set up in order to raise awareness of transversal skills among faculty members and students alike.

\section{Findings}

\subsection{Summary of the Survey}

From the survey the following conclusions could be drawn:

In general, our industry partner do have a very good impression of our students. The knowhow of our graduates as well as their content expertise got mentioned several times. In addition, they were also quite satisfied with the foreign language skills of our students. Since some of the companies do have English as the working language, our industry 
partners highlighted that it is surprisingly natural for our graduates to switch to English in meetings and telephone conferences and during company visits.

Secondly, the online survey stressed that the future of employability needs to be addressed more closely at higher education as digitalization will cause some changes in employees's skill set. Content expertise will no longer guarantee well-paid and successful jobs, future employees will have to bring along more competencies and skills which may usually go beyond their compfort zone. An IT engineer, for example, will not only have to take care of the company's IT infrastructure, he or she will also have to negotiate software contracts, lead a team of experts, and will eventually have to rely on his entrepreneurial skills when starting an own business. Due to globalization working abroad and regular business travels might also be part of the job description as well as social skills and sound communicative competence.

When describing the skills of a T-shaped engineer the answers were manifold. Some mentioned leadership skills, an entrepreneurial mindset, communications skills in German and in English, advanced writing styles, negotiation skills, background in economics, spirit of innovation, commitment, independent work and creativity. In terms of training and further education, respondents stressed the importance of life-long learning and the benefit of a growing mindset that "you never stop learning".

\subsection{SWOT Analysis}

The results of the online survey were discussed in several faculty meetings. The final meeting was based on a so-called SWOT analysis. Figure 1 is a visual representation of the main results. In the SW 

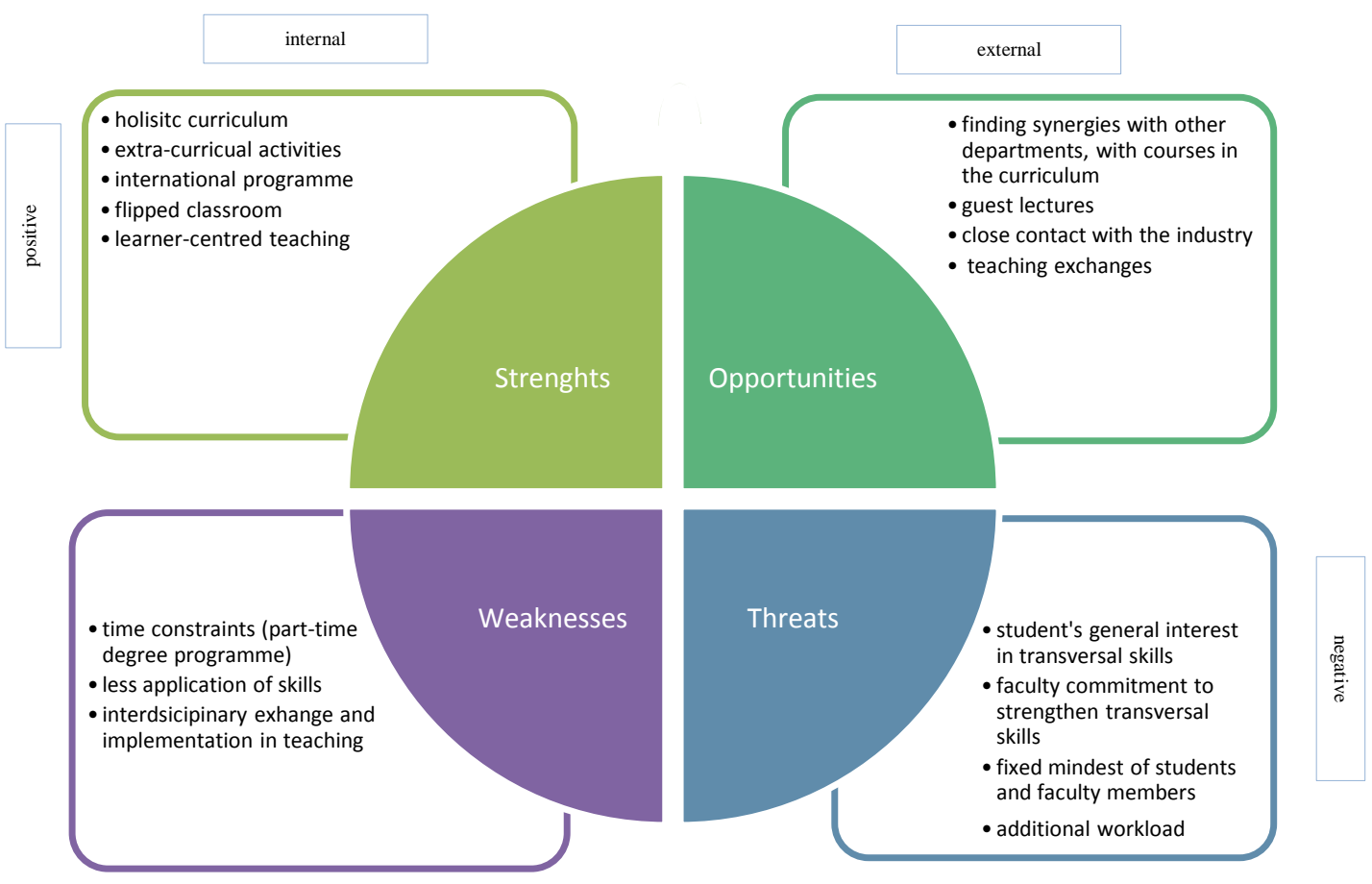

Figure 2. SWOT Analysis Transversal skills

Following on from the SWOT analysis, an action plan was set up to address the differen areas of the SWOT anaylsis. Since several topics would need intensive planning and could not be implemented ad hoc, the faculty agreed to implement a professional training week for students in order to strengthen their T-shaped mindset. The aim of the training week was to remind students of their acquired skills and competencies. In doing so, several key issues based in the SWOT analysis were addressed before students started to apply for an internship or a position in a company. In other words, this boost in self-confidence should make our future graduates more aware of who they are, what they know and what asset they bring to the respective company.

\subsection{Professional TrainingWeek@ IIT}

The professional training week has a T-shaped designed. Workshops, counselling sessions, feedback meetings and events were set up in the light of transversal skills. The working language of the whole week was English. The following overview should give an insight into the different activities: 
Table 1. Professional week at a glance.

\begin{tabular}{|c|c|c|c|c|c|}
\hline & Monday & Tuesday & Wednesday & Thursday & Friday \\
\hline $\begin{array}{l}\text { Morning } \\
\text { Session }\end{array}$ & Teambuilding & $\begin{array}{l}\text { Entrepreneurial } \\
\text { Management }\end{array}$ & $\begin{array}{l}\text { Insights into } \\
\text { Assessment } \\
\text { Centers }\end{array}$ & $\begin{array}{l}\text { Client } \\
\text { Interaction } \\
\text { Skills }\end{array}$ & $\begin{array}{l}\text { "Sales Pitch" } \\
\text { Appathlon }\end{array}$ \\
\hline $\begin{array}{l}\text { Afternoon } \\
\text { Session }\end{array}$ & $\begin{array}{l}\text { Written } \\
\text { Communication }\end{array}$ & $\begin{array}{l}\text { Leadership } \\
\text { Development }\end{array}$ & $\begin{array}{l}\text { Polishing } \\
\text { your CV and } \\
\text { perfecting job } \\
\text { interviews }\end{array}$ & $\begin{array}{l}\text { Decision } \\
\text { Making \& } \\
\text { Critical } \\
\text { Thinking }\end{array}$ & Social Event \\
\hline
\end{tabular}

\section{Discussion and further implications}

Without a doubt, the job market has undergone a huge transformation in the last couple of years. Due to digitalization and the introduction of the so-called 4th industrial revolution the employment landscape is rapidly changing. The field of engineering is deeply affected by this development as they build the centre of this transformation. In fact, future careers are just beginning to emerge and ordinary skills and education will no longer suffice in order to meet the challenges of the future. As more and more tasks are automated human skills become more valuable. In line with Gray (2016), these skills are

1. Complex Problem Solving

2. Critical Thinking

3. Creativity

4. People Management

In terms of life-long learning and education, stakeholders and educational institution will thus have to reconsider their strategic orientation to make graduates ready for the future.

\section{References}

Bahler, K. (2018). The people have the hottest job in Americe. Here's what they say it's really like. Time. Retrieved from http://money.com/money/5138428/how-to-besoftware-developer-best-job/.

Braun, V., \& Clarke, V. (2006). Using thematic analysis in psychology. Qualitative Research in Psychology, 3(2), 77-101. https://doi.org/10.1191/1478088706qp063oa

Gao, C. Y., \& Peng, D. H. (2011). Consolidating SWOT analysis with nonhomogeneous uncertain preference information. Knowledge-Based Systems, 24(6), 796-808. 
Grasso, D. \& Brown Burkins, M. (Eds.). (2010). Holistic engineering education: Beyond technology. New York, NY: Springer.

Gray, A. (2016). The 10 skills you need to thrive in the fourth industrial revolution. Retrieved from World Economic Forum. Retrieved, from https://www.weforum.org/agenda/2016/01/the-10-skills-you-need-to-thrive-in-thefourth industrial-revolution/.

Gürel, E., \& Tat, M. (2017). SWOT ANALYSIS: A THEORETICAL REVIEW. Journal of International Social Research, 10(51).

Tranquillo, J. (2017). The T-Shaped Engineer. Journal of Engineering Education Transformations, 30(4), 12-24. 